\title{
Perceived Role of Dietary Fiber in Healthy Diet and its Intake Pattern among Educated Urban Population
}

\author{
Abu Torab M. A. Rahim * and Rumana Choudhury \\ Institute of Nutrition and Food science, University of Dhaka, Dhaka-1000
}

\begin{abstract}
Dietary fiber (DF) is now considered as a part of healthful diet because it plays an important role in preventing many of organic diseases. A survey was conducted to evaluate the perceived role of DF in healthy diet and its intake level among educated urbanites of Dhaka city. For dietary information, a 24 hours recall method along with a 7 day food frequency questionnaire was used. The findings show that the respondents were aware of DF and were able to name fiber rich foods. They perceived that fruits and vegetables are the rich source of DF. But fiber consumption frequencies showed that majority of them do not take fruits and vegetables everyday. As a result DF intake of the respondents was found $7.87 \mathrm{~g} /$ day, far below the recommended level (25-35 g/day or 10 $\mathrm{g} / 1000 \mathrm{Kcal})$. Thus the study revealed that though the health benefits of DF was perceived and recognized by our educated population but they do not practice it.
\end{abstract}

Key Words: Dietary fiber, Perception, Consumption profile

\section{Introduction}

Dietary fiber includes polysaccharides, oligosaccharides, and associated plant substances that are resistant to digestion and adsorption in the human small intestine with complete or partial fermentation in the large intestine ${ }^{1}$. DF of different composition and physicochemical properties produce different beneficial physiological effects including laxation, and blood cholesterol and glucose attenuation ${ }^{1}$. Besides, fiber component of the diet is nutritionally important because of their properties like bulk density, hydration capacity, binding properties and fermentability. Therefore, experts generally recommend increased DF intake by increasing consumption of grains, legumes, vegetables, and fruits rather than by taking supplements ${ }^{1}$. This notion, hence, implies the need of data on the DF content and composition of foods for epidemiologist, research scientists, and dietitians. A number of studies on the content and composition, and physiological role of DF of Bangladeshi foodstuffs have been conducted in our laboratory ${ }^{2-4}$.

To reach the recommended level of DF intake, data on evaluating the natural intake pattern of DF among the general population are important. This is because modern

Bangladesh Journal of Nutrition. Vol 18-19, December 2005-2006. Institute of Nutrition and Food Science, University of Dhaka-1000, Bangladesh.

* Author for correspondence 
societies seem to be converging on a pattern of diet high in saturated fat, sugar, and refined foods and low in fiber - often termed the "Western diet." Many see this dietary pattern to be associated with high levels of chronic and degenerative diseases. Bangladesh is no exception of this phenomenon called "The Nutrition Transition". Traditionally, the nutrition transition is described as a change from traditional, indigenous, rural, high-fiber, low-fat diet eaten by poorer people to a more affluent, western-type of diet rich in animal fats and low in fiber ${ }^{5}$. In a recent study Rahim et al., identified that the fast food culture is an inevitable phenomenon among the young urbanites $^{6}$. With more and more people are taking western diet, they are devoid of traditional non-refined fiber rich foods. In this context the present study evaluated consumers' perceived role of DF in the health, their knowledge of fiber rich foods sources, and their DF intake profile.

\section{Methodology}

Study design

A cross-sectional survey on perceived role and intake pattern of DF was conducted with 400 respondents, mainly students who were doing their graduation and post graduation courses in various educational institutions of Dhaka city and its suburban areas viz., Dhaka University, Jahangir Nagar University, Dhaka City College, Dhaka College, and Eden College. A number of graduate/postgraduate service holders working in various organizations in Dhaka were also included in the study. A quota sampling design was followed to select the sample population of the study.

\section{Data collection instrument and its validation}

The data collection tool comprised the followings: semi-structured questionnaire, standard plate, and standard bowls for dietary estimations. The questionnaire contained specific questions on knowledge, attitude and perceived role on DF in health and disease. This was validated in a pilot survey conducted among 40 respondents.

\section{Method of dietary survey}

Respondents' DF consumption was assessed by a 24 hours recall method along with a 7 day food frequency questionnaire. The type and amount of food eaten outside the home was also recorded as part of the meals taken by each individual. For estimation of the amount of food consumed by the respondents during the last 24 hours, standardized utensils were shown to the respondents and asked them to indicate the quantity of food equal to the portion size of the utensil they actually consumed. The portion size was noted and later used for calculation of DF with the help of standard food conversion table ${ }^{7}$. The dietary survey was performed for 1 day. DF intake per person was calculated by substituting the fiber content of each food in the Food Composition Table of INFS ${ }^{8}$. Resistant starch was not calculated because of a lack of data. For the assessment of respondents' usual consumption pattern of fiber rich food, a food frequency questionnaire was prepared and attached with the questionnaires. 


\section{Statistical analysis}

Descriptive statistics are reported as percentages using whole numbers. The Chisquared test was used to evaluate correlation between dependent and independent variables of the study population. Significance level was set at 0.05 . Microsoft Excel worksheet was used to construct contingency tables followed by cross table statistics with the statistical package SPSS, version 13.0

\section{Results}

The relevant socio-demographic characteristics of the study participants are presented in Table 1. Majority of the respondents were students (89.3\%) and a large portion of them were from affluent families $(40 \%)$ relative to the economic classification of the group.

\section{Perception of Dietary Fiber and its Health Benefits}

Before evaluating the perception and attitude towards DF, respondents' knowledge of nutrients and their function were tested. Only $11.5 \%$ (46) of them did not know anything about the nutrients of food. The rest of the respondents

Table 1. Socio-demographic Features of the Respondents $(n=400)$

\begin{tabular}{|l|l|l|}
\hline \multicolumn{1}{|c|}{ Variables } & \multicolumn{1}{|c|}{ Frequency } & \\
\hline Sex & \multicolumn{1}{|c|}{$\%$} \\
\hline Male & 168 & 42.0 \\
\hline Female & 232 & 58.0 \\
\hline Age group & & \\
\hline $18-24$ yrs & 335 & 83.75 \\
\hline $25-44$ yrs & 65 & 16.25 \\
\hline Occupation & & \\
\hline Student & 357 & 89.25 \\
\hline Service/ Others & 43 & 10.75 \\
\hline Education & & \\
\hline HSC-Graduate & 316 & 79.0 \\
\hline$\geq$ Graduate & 84 & 21.0 \\
\hline Monthly family income & & \\
\hline ITk. 4,999 & 21 & 5.25 \\
\hline Tk. 5,000-Tk. 14,999 & 219 & 54.75 \\
\hline$\geq$ Tk. 15,000 & 160 & 40.00 \\
\hline
\end{tabular}

$98.5 \%$ (349) correctly mentioned different nutrients of food with a total citation of 1023 . But almost one-third of the respondents $(22.3 \%)$ did not know or heard about food fiber or dietary fiber. When asked to name five rich food sources of DF, the respondents came out with huge number of food items scattered throughout different food groups. They mentioned a total of 79 food items with a total citation of 884 . These foods were divided into commonly known food groups and presented in Figure 1. Results showed that 
somehow or other, majority of the respondents identified correctly vegetables and fruits as good source of DF but overlooked the importance of cereals as DF rich source in terms of fiber density $(\mathrm{g} / 1000 \mathrm{kcal})$.

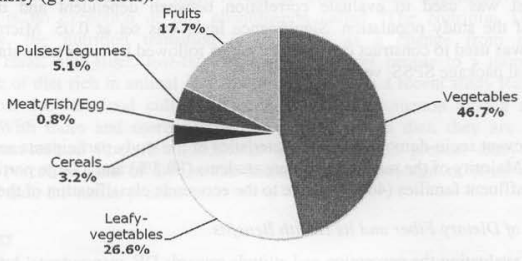

Figure 1. Respondents' perception towards fiber rich food

Majority of the respondents perceived that DF is good for health $(67 \%)$ but onefourth of them (24\%) did not have any idea about what and how DF exerts its beneficiary effect on health and nutrition (Table 2).

\section{Daily Intake and Consumption Frequency of Dietary Fiber}

Among the 400 participants, 250 participants gave their consent to the 24 hours dietary recall part of the study. The findings are presented in Table 3 and Figure 2. Results show that the average DF consumed by the respondent was $7.87 \mathrm{~g} /$ day. And most of the DF intake was contributed by the consumption of vegetables and pulses of the respondents' daily diet. Daily DF intake from other grain group was mainly from flour based products like rooti.

Table 2. Respondents' Perceived Role of Dietary Fiber in Health

\begin{tabular}{|c|c|}
\hline Questions & $\begin{array}{l}\text { Response Frequency } \\
\text { (\% of total response) }\end{array}$ \\
\hline A. Is Dietary Fiber good for health? & $268(67.0)$ \\
Yes & $36(9.0)$ \\
No & $96(24.0)$ \\
No Idea & $178(44.5)$ \\
B. If yes why (mention any three reasons)? & $52(13.0)$ \\
Correct answer & $73(18.3)$ \\
Incorrect answer & $26(6.5)$ \\
Can't explain the reason & $3(0.8)$ \\
C. If no why (mention any three reasons)? & $4(1.0)$ \\
Can't explain the reason & \\
Cause digestion, bowl, etc. problems & \\
Contain nothing (i. e. nutrient) & \\
\hline
\end{tabular}


Table 3 Respondents' DF Consumption Profile $(\mathbf{n}=\mathbf{2 5 0})$

\begin{tabular}{|r|r|r|r|}
\hline DF intake (g/day) & \multicolumn{2}{|c|}{$\begin{array}{l}\text { Response Frequency } \\
\text { (\% of total response) }\end{array}$} & \multicolumn{2}{|c|}{ Average of total (g/day) } \\
\cline { 3 - 4 } & & Mean \pm SD & Range \\
\hline $0-10.99$ & $192(76.8)$ & & \\
$11-25.99$ & $52(20.8)$ & $7.87 \pm 6.49$ & $0.25-42.22$ \\
$26-45.00$ & $6(2.4)$ & & \\
\hline
\end{tabular}

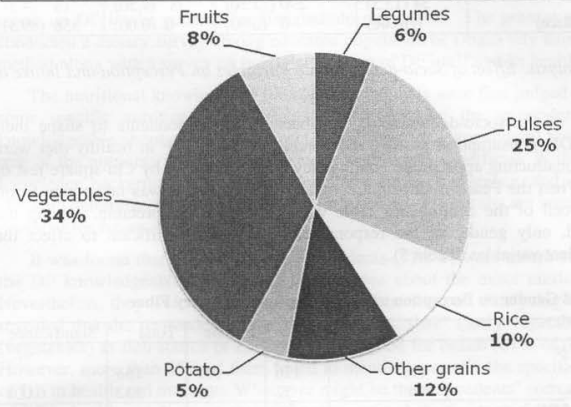

Figure 2 Percentage of DF intake by food group against total DF intake

However, consumption frequency of DF rich foods in vegetables food group of the participants was found unsatisfactory. Less than half of the respondents consumed vegetables everyday of the week (Table 4). Fruits consumption frequency was found also poor. Consumption frequency of selected fiber rich vegetables revealed the following most cited fiber rich vegetables in terms of the percent of total citation: Palang shak $(80 \%)$, Lau shak $(77 \%)$, and Pat shak (50\%) among leafy-vegetables; Alu (93\%), Gajar $(80 \%)$, and Kochu $(60 \%)$ among underground vegetables; Data $(64 \%)$ and Kochu loti $(60 \%)$ among tuber vegetables; Motorsuti $(87 \%)$, Shim $(79 \%)$, and Borboti $(73 \%)$ among beans; Tomato $(94 \%)$, Lau $(84 \%)$, Mistikumra $(83 \%)$, and Dherosh $(81 \%)$ among fruit vegetables; and Fulcopy (94\%) among flower vegetables. 
Table 4. Respondents' Consumption Frequency of DF rich Food

\begin{tabular}{|l|r|r|r|r|}
\hline \multirow{2}{*}{ Foods Groups } & \multicolumn{4}{|c|}{ Frequency (\% of respondent) } \\
\cline { 2 - 5 } & \multicolumn{1}{|c|}{ 0/week } & 1 - 3 /week & \multicolumn{1}{|c|}{4 -6/week } & \multicolumn{1}{c|}{$7 /$ week } \\
\hline Vegetable & $0(0.00)$ & $83(20.75)$ & $136(34.00)$ & $181(45.3)$ \\
Fruit & $5(1.25)$ & $188(47.00)$ & $137(34.25)$ & $70(17.5)$ \\
Pulses & $6(1.50)$ & $89(22.25)$ & $119(29.75)$ & $186(46.5)$ \\
Legumes & $54(13.5)$ & $290(72.50)$ & $38(9.50)$ & $18(4.5)$ \\
Cereal (except Rice) & $0(0.00)$ & $0(0.00)$ & $0(0.00)$ & $358(89.5)$ \\
\hline
\end{tabular}

Cross-table Analysis: Effect of Socio-demographic Variables on Perception and Intake of $D F$

The effect of the socio-demographic variables of the respondents to shape their knowledge of DF, consumption profile, and perceived role of DF in healthy diet were evaluated by constructing appropriate contingency tables followed by Chi-square test of significance. When the Pearson Chi-square value is $<0.05$ then it was taken significant result and the cell of the contingency table was considered interpretable. Among the variables tested, only gender of the respondents was found significant to affect the selected dependent variables (Table 5).

Table 5. Effect of Gender on Perception and Consumption of Dietary Fiber

\begin{tabular}{|c|r|r|r|r|}
\hline \multicolumn{1}{|c|}{$\begin{array}{r}\text { Variables } \\
\text { Yes }\end{array}$} & Male & Female & Total & Significance \\
\hline A. DF Knowledge & 116 & 195 & 168 & \\
& 52 & 37 & 232 & 0.001 \\
\hline B. Perception of DF as a nutrient & & & & \\
Yes & 65 & 86 & 151 & \\
No & 41 & 86 & 127 & 0.005 \\
No idea & 12 & 21 & 33 & \\
No response & 50 & 39 & 89 & \\
\hline Y. Perception that DF is good for health & & & & \\
Yes & 91 & 177 & 268 & \\
No & 14 & 22 & 36 & 0.000 \\
No idea & 63 & 33 & 96 & \\
\hline D. Role of DF in health and disease are & & & & \\
Correct answer & 42 & 102 & 144 & \\
Incorrect answer & 18 & 32 & 50 & 0.162 \\
Non responsive & 31 & 43 & 74 & \\
\hline
\end{tabular}

\section{DISCUSSION}

An increased DF intake would be beneficial and many countries have their recommended levels of DF intake, for example $20-35 \mathrm{~g} /$ day in $\mathrm{USA}^{9}$ and $20-25 \mathrm{~g} /$ day in $\operatorname{Japan}^{10}$. Unfortunately no such recommendation has been set for Bangladesh. However, it is generally believed that our diet is rich in food fiber though western type food 
behaviour i.e., high calorie low fiber diet is gradually replacing the tradition-bound food culture of Bangladesh. Nevertheless, increased intake of DF through diet should be promoted. But it is very difficult to reach the recommended level. A possible reason is due to lack of reports which is presenting a problem in the overall promotion of health in the population today.

In order to develop practical measures to increase DF intake, the natural DF intake pattern among the general population should be considered. However, there is so far no report on DF intake patterns for Bangladeshi population. The present study, therefore, conducted a dietary survey among educated population of Dhaka city using dietary recall method along with a survey on public perception of DF itself and its health benefits.

The nutritional knowledge of the study participants were first judged by asking them some specific nutrition related questions. Majority of the respondents were found knowledgeable about some basic aspect of nutrition (data not shown) but their perceived role of the nutrients in health and diseases were found superficial. With this nutritional knowledge background of the respondents, perception, preference, and intake profile of DF were determined by a pre-tested study instrument. The results are interesting and have potential for future investigations.

It was found that majority of the respondents $(77.8 \%)$ were aware of DF but half of the DF knowledgeable respondents had no idea about the exact nutrition role of DF. Nevertheless, they were able to name DF rich food sources. Analyzing the responses, it revealed that the respondents viewed, in general, "shak" (leafy vegetables) and "sabji" (vegetables) as rich source of DF and they are good for health (67\% of the respondents). However, more than $55 \%$ of them failed to mention correctly the specific beneficial role of DF in health and nutrition. What ever might be the respondents' correct perceived role of DF in health and diseases, their DF consumption behaviour was found contradictory to their knowledge and attitudes. Only $45 \%$ and less than $18 \%$ of the respondents consume vegetables and fruits respectively everyday in a week (Table 4).

This is why the average DF intake was found $7.87 \mathrm{~g} /$ day, far below the recommended daily dietary intake of $20-35 \mathrm{~g}^{-\mathrm{day}^{9}}$ or $10 \mathrm{gm} / 1000 \mathrm{Kcal}^{11}$. It is difficult to compare the daily dietary intake level of DF among the respondents because all nutrition surveys conducted in Bangladesh did not document intake pattern of food fiber. However, this intake level is somewhat higher than our earlier estimation of fiber intake among residential students of Dhaka University through direct food analysis (2.79-3.23 $\mathrm{g}$ NDF per $100 \mathrm{~g}$ meals per day on fresh weight basis) ${ }^{12}$. The current estimation of daily DF intake among educated urbanites, however, might be an underestimation because most of the food composition tables of Bangladesh listed food fiber as crude fiber for most of the foods. Crude fiber value is an underestimated value than DF value ${ }^{2,3}$. Therefore the actual DF consumption could be higher if DF values are used in food fiber calculation. Nevertheless, the study disclosed the need to develop awareness to consume high DF (> $25 \mathrm{~g} /$ day) among Bangladeshi consumers as a part of healthful diet. 


\section{REFERENCES}

1. Association of American Cereal Chemists. The definition of dietary fiber. Cereal Food World 2001; 46:112-6.

2. Rahim ATMA, Jerin I, and Rahman SMM. Total dietary fiber and retention factors of Bangladeshi foods prepared by customary cooking process. Dhaka Univ J Biol Sci 2008; 17(1): 9-16.

3. Huq F, Fatema K, and Rahim ATMA. Content and composition of dietary fiber in some Bangladeshi vegetables. Diab Endocr J 2001; 29(2):61-6.

4. Khan MR, Mamun SA, Hasin A, Choudhury UF, and Ahmed F. Effect of different dosages of ispagula husk on serum lipid profile. Dhaka Univ J Biol Sci 1996; 5(1):61-68.

5. Popkin BM. The nutrition transition and its health implications in lower-income countries. Pub Health Nutr 1998; 1:5-21.

6. Rahim ATMA, Aziz F, Shaheen S, and Bhuyan MAH. Perception and preference of fast food and traditional snack food by selected urban population. Bangladesh J Physiol Pharmacol 2001; 17(2): 58-62.

7. Ali SMMK and Pramanik MMA. Conversion factor and dietary calculation, Institute of Nutrition and Food Science, University of Dhaka, Dhaka, 1991.

8. Institute of Nutrition and Food Science. Deshio Khaddyer Poostimann (Food Value of Local Foods), University of Dhaka, Dhaka, 1992, (in Bangla).

9. American Dietetic Association Report. Position of the American Dietetic Association: Health implications of dietary fiber. J Am Diet Assoc 2002; 102 (7):993-1000.

10. Ministry of Health, Welfare and Labor. Recommended Dietary Allowances for dietary fiber. In: Recommended Dietary Allowance for the Japanese 5th edn. Daiich Shuppan Press, Tokyo, 1994, pp 58-59, (in Japanese).

11. Cummings JH and Englyst NH. Gastrointestinal effects of food carbohydrates. Am J Clin Nutr (suppl) 1995; 61:1938S-45S.

12. Mahmood F. Dietary Fiber of some Bangladeshi Foods and Meals: A Compositional Analysis, M Sc Thesis, Institute of Nutrition and food Science, University of Dhaka, Dhaka, 1999. 